\title{
Pedagogia histórico-crítica: que pedagogia é essa?
}

\author{
Raquel Elisabete de Oliveira Santos*
}

\begin{abstract}
Resumo
O presente artigo é parte constitutiva de pesquisa em andamento intitulada "Estudo das tentativas de restruturação do currículo para a efetivação de uma pedagogia histórico-crítica: acompanhamento e registro do processo em uma escola de Ensino Fundamental I do município de Jundiaí", que toma como perspectiva metodológica a epistemologia materialista histórico-dialética e por meio da qual, busca-se apreender o processo que se desdobra em uma escola pública que se propõe à implementação da pedagogia histórico-crítica. Nesse artigo, a partir de um levantamento bibliográfico, busca-se apresentar ao leitor um panorama acerca da pedagogia histórico-crítica, descrevendo como, a partir dessa perspectiva teórica, são pensados a sociedade, a escola, os conteúdos, o currículo e o método de ensino.
\end{abstract}

Palavras-chave: Pedagogia histórico-crítica; Educação escolar; Transformação social.

\section{Historical-critical pedagogy: what pedagogy is this?}

\begin{abstract}
This article is part of an ongoing research study entitled "Study of attempts to restructure the curriculum for the accomplishment of a historical-critical pedagogy: follow-up and registration of the process in a Primary School I of the municipality of Jundiaí", which takes as a methodological perspective to the historical-dialectical materialist epistemology and through which, one seeks to apprehend the process that unfolds in a public school that proposes to the implementation of historical-critical pedagogy. In this article, based on a bibliographical survey, the article seeks to present to the reader a panorama about historical-critical pedagogy, describing how, from this theoretical perspective, society, school, contents, curriculum and method are thought of education.

Keywords: Historical-critical pedagogy; Schooling; Social transformation.
\end{abstract}

\section{Introdução}

O presente artigo, que tem como objetivo específico explicitar alguns pontos principais da pedagogia histórico-crítica, a partir de um cuidadoso levantamento bibliográfico, tendo como referências os principais autores acerca dessa pedagogia, quais sejam: Dermeval Saviani; Newton Duarte; Lígia Márcia Martins; Júlia Malanchen e Ana Carolina Galvão Marsiglia, é parte constitutiva da pesquisa intitulada "Estudo das tentativas de restruturação do currículo para a efetivação de uma pedagogia histórico-crítica: acompanhamento e registro do processo em uma escola de Ensino Fundamental I do município de Jundiaí”.

A pesquisa supracitada tem por objetivo apreender o processo de tentativa de implementação da pedagogia histórico-crítica, enquanto diretriz pedagógica, em uma escola do município de Jundiaí, por meio de um percurso de formação em grupo sob a perspectiva do método da pedagogia histórico-crítica, proposto por Dermeval Saviani.

Há, portanto, na pesquisa, o objetivo de analisar e compreender o referido processo vivenciando as eventuais materializações de mudanças no currículo prescrito da escola e na atuação prática dos professores.

O texto a seguir, como já mencionado, constitui-se a partir de um levantamento bibliográfico que tem como fontes obras de Dermeval Saviani e de outros importantes pesquisadores da pedagogia histórico-crítica. Organiza-se em seções pautadas na intencionalidade de oferecer ao leitor a possiblidade de conhecer a pedagogia histórico-crítica, entendendo como são pensados a sociedade, a escola, os conteúdos e o conhecimento, o currículo e o método a partir dessa teoria pedagógica.

\section{Que pedagogia é essa? Ideal de sociedade e escola necessária}

O termo pedagogia histórico-crítica foi cunhado por Dermeval Saviani em 1978 e refere-se a uma perspectiva pedagógica que, surge num contexto de busca por saídas teóricas que superassem os limites apresentados pelas teorias crítico-reprodutivistas. É uma perspectiva pedagógica que "se diferencia no bojo das concepções críticas; ela diferencia-se da visão

\footnotetext{
*Endereço Eletrônico:raqlisa@hotmail.com
} 
crítico-reprodutivista, uma vez que procura articular um tipo de orientação pedagógica que seja crítica sem ser reprodutivista" (SAVIANI, 2013, p. 3). Ademais, assume um compromisso explícito com a transformação da sociedade e com a luta socialista:

Em relação à opção política assumida por nós, é bom lembrar que na pedagogia histórico-crítica a questão educacional é sempre referida ao problema do desenvolvimento social e das classes. A vinculação entre interesses populares e educação é explícita. Os defensores da proposta desejam a transformação da sociedade. Se este marco não está presente, não é da pedagogia histórico-crítica que se trata. (SAVIANI, 2013, p.72)

Duarte e Saviani (2015, p. 9) afirmam, ainda, que "o domínio do conhecimento é uma das armas que a classe dominante emprega para neutralizar as ações potencialmente revolucionárias”. Para Duarte e Saviani $(2015$, p. 2) "a luta pela escola pública coincide com a luta pelo socialismo", uma vez que cumpra, de fato, seu papel, garantirá a socialização dos conhecimentos construídos historicamente pelos homens no processo de produção das condições materiais de vida e que compõe os meios de produção:

Tal tese está apoiada na análise de uma contradição que marca a história da educação escolar na sociedade capitalista. Trata-se da contradição entre a especificidade do trabalho educativo na escola - que consiste na socialização do conhecimento em suas formas mais desenvolvidas - e o fato de que o conhecimento é parte constitutiva dos meios de produção que, nesta sociedade, são propriedade do capital e, portanto, não podem ser socializados. (DUARTE; SAVIANI, 2015, p. 2)

Saviani (2008) apresenta a pedagogia histórico-crítica como possibilidade de superação das pedagogias crítico-reprodutivistas: Teoria do sistema de ensino como violência simbólica, Teoria da escola como aparelho ideológico do Estado e Teoria da escola dualista. Essas, embora cumpram importante papel ao apresentar um caráter crítico, levando em conta os determinantes sociais da educação, são pessimistas e deterministas uma vez que não vislumbram possibilidade alguma de que a escola possa contribuir para a transformação social, servindo apenas à reprodução das relações sociais vigentes. Para as teorias crítico-reprodutivistas a escola na sociedade capitalista não terá outra função que não seja a reprodução dos interesses do capital, a manutenção das desigualdades e dos interesses hegemônicos.

Essas teorias são críticas, pois orientam a compreensão da educação considerando seus condicionantes sociais. Há a percepção da dependência da educação em relação à sociedade, mas não há proposição de uma proposta pedagógica. Empenham-se, portanto, tão somente em explicar o mecanismo de funcionamento da escola, tal como ela está constituída. Tendo um caráter reprodutivista, estas teorias consideram que a escola não poderia ser diferente do que é.

Enquanto as teorias não-críticas pretendem
ingenuamente resolver o problema da
marginalidade por meio da escola, sem jamais
conseguir êxito, as teorias crítico-reprodutivistas
explicam a razão do suposto fracasso. Fracasso
que é, na verdade, o êxito da escola, aquilo que
se julga ser uma disfunção é antes, a função
própria da escola. Com efeito, sendo um
instrumento de reprodução das relações de
produção, a escola na sociedade capitalista
necessariamente reproduz a dominação e
exploração. Daí seu caráter segregador e
marginalizador. (SAVIANI, 2008, p. 24)

Destarte, as pedagogias críticoreprodutivistas têm importante papel de denúncia da educação oficial como instrumento a serviço dos dominantes, de manutenção das condições vigentes, mas não apresentam alternativas de superação do problema apontado. Dessa forma, a educação é vista descolada de seu contexto histórico.

A pedagogia histórico-crítica compreende que a escola é determinada socialmente e que a sociedade, fundada no modo de produção capitalista, é dividida em classes com interesses opostos, portanto, a escola sofre a determinação do conflito de interesses que caracteriza a sociedade. A classe dominante não tem interesse na transformação histórica da escola, pois quer preservar seu domínio.

Nesse sentido, uma teoria crítica (que não seja reprodutivista) só poderá ser formulada do ponto de vista do interesse dos dominados, assumindo a escola como um instrumento de luta contra a marginalidade, o que significa engajar-se no esforço para garantir aos trabalhadores um ensino da melhor qualidade possível nas condições históricas atuais.

A pedagogia histórico-crítica busca compreender a educação no seu desenvolvimento 
histórico-objetivo situando-a no processo de transformação histórica e assumindo um compromisso com a transformação social em defesa dos interesses dos dominados. Saviani destaca que para a pedagogia histórico-crítica:

$\mathrm{O}$ problema permanece em aberto. $\mathrm{E}$ pode ser recolocado nos seguintes termos: é possível encarar a escola como uma realidade histórica, isto é, suscetível de ser transformada intencionalmente pela ação humana? Evitemos escorregar para uma posição idealista e voluntarista. Retenhamos da concepção crítico reprodutivista a importante lição que nos trouxe: a escola é determinada socialmente; a sociedade em que vivemos, fundada no modo de produção capitalista, é dividida em classes com interesses opostos; portanto, a escola sofre a determinação do conflito de interesses que caracteriza a sociedade. Considerando-se que a classe dominante não tem interesse na transformação histórica da escola (ela está empenhada na preservação de seu domínio, portanto, apenas acionará mecanismos de adaptação que evitem a transformação histórica da escola), segue-se que uma teoria crítica (que não seja reprodutivista) só poderá ser formulada do ponto de vista dos interesses dos dominados. (SAVIANI, 2008, p.25)

Saviani (2013, p. 14) defende o papel da escola como instituição a serviço da socialização do saber sistematizado, afirmando que "a escola diz respeito ao conhecimento elaborado, e não ao conhecimento espontâneo; ao saber sistematizado e não ao saber fragmentado; à cultura erudita, não à popular". Defende-se, portanto, a educação escolar em sua especificidade pedagógica e educativa, em sua função de socialização dos conhecimentos artísticos, científicos e filosóficos produzidos pelo homem ao longo da história.

A pedagogia histórico-crítica defende a escola como espaço da educação formal em sua especificidade, que é a prática do ensino dos produtos do saber científico em suas formas mais desenvolvidas, dos conhecimentos historicamente sistematizados por meio dos quais ocorrerá a humanização dos indivíduos com o desenvolvimento de suas funções psicológicas superiores.

Cabe salientar que a Pedagogia históricocrítica firma suas bases filosóficas, político-sociais, históricas e econômicas no materialismo históricodialético e em reflexões marxistas (de Marx e de outros teóricos como Gramsci, Vigotski, Lênin,
Engels), que tiveram os estudos de Marx e Engels como referencial e inspiração. Destarte, a pedagogia Histórico-crítica considera a educação e a escola situadas historicamente; a constituição do homem em seu processo histórico de objetivação por meio do trabalho, processo no qual produz conhecimento ao criar suas condições de existência; o papel desses conhecimentos na sociedade capitalista enquanto parte integrante dos meios de produção; a apropriação desses conhecimentos pela classe dominante e seu uso como ferramenta de dominação. A partir dessas referências, a pedagogia histórico-crítica vai pensar a escola, em especial, a pública, como espaço de luta da classe trabalhadora. A escola que assume seu papel de socialização dos conhecimentos historicamente sistematizados, servirá como instrumento que dá à classe explorada a possibilidade de dominar aquilo que os dominantes dominam e, por conseguinte, lutar contra o poder dominante, lutar pelo comunismo.

Esse caráter atribuído à pedagogia históricocrítica de luta pelo comunismo é assumido explicitamente em textos dos autores utilizados como aporte para esse artigo. Há a assunção do compromisso com a transformação social, com a superação das condições de exploração, de dominação e de violência instaladas que marcam o sistema capitalista. Tal superação ocorrerá pela instalação do socialismo, como período de transição para o comunismo. Por conseguinte, a pedagogia Histórico-crítica articula-se com a construção de uma sociedade sem classes, uma sociedade comunista.

A pedagogia histórico-crítica coloca-se, portanto, a serviço da luta pelo socialismo, como um período de transição para o comunismo. Objetiva-se, portanto, a construção de uma sociedade sem classes, com o fim das formas de exploração do homem pelo homem, numa sociedade nova, na qual a democracia passe a ser real e não apenas formal, uma vez que o poder, seja, de fato, exercido pelo povo.

\section{Quem é o aluno e quem é o professor?}

$\mathrm{Na}$ perspectiva da pedagogia históricocrítica, alunos e professores são vistos como agentes sociais que se diferenciam no ponto de partida do processo educativo em relação ao conhecimento ora tomado como objeto de ensino: enquanto professores têm uma compreensão sintética precária, alunos têm uma compreensão sincrética do conteúdo. Não haverá centralidade no professor, 
como na Pedagogia tradicional, ou no aluno, como nos métodos novos, mas sim, no conhecimento, que será eixo da prática que tem professores e alunos como agentes.

Professores e alunos são considerados agentes sociais, chamados a desenvolver uma prática social, centrada não na iniciativa do professor (pedagogia tradicional) ou na atividade do aluno (pedagogia nova), mas no encontro de seus diferentes níveis de compreensão da realidade por meio da prática social comum a ambos. (BATISTA e LIMA, 2012, p. 7)

Destarte, os alunos são, na pedagogia histórico-crítica, tomados como sínteses de múltiplas determinações, como indivíduos concretos, o que a diferencia das pedagogias tradicional e moderna. De acordo com Saviani (2015, p. 79), enquanto na pedagogia tradicional os educandos são considerados como indivíduos abstratos, como "expressões particulares da essência universal que caracterizaria a realidade humana", na pedagogia moderna os indivíduos são considerados indivíduos empíricos, lhes sendo atribuída centralidade no processo educativo, em função de sua originalidade, criatividade e autonomia. Na pedagogia histórico-crítica os alunos são tomados como indivíduos concretos, constituídos por uma multiplicidade de relações e determinações numerosas, "portanto, o que é do interesse deste aluno concreto diz respeito às condições em que se encontra e que ele não escolheu". Dessa forma, é possível negar a ideia de que o aluno pode fazer tudo a sua própria escolha, já que condiciona-se a um contexto que lhe é dado em termos sociais e históricos.

Saviani (2015) ressalta, ainda, que é para esse aluno concreto que o professor deverá possibilitar a assimilação dos conhecimentos, já que será por meio do ensino que haverá a promoção do desenvolvimento do indivíduo. No entanto, nem sempre, os interesses imediatos do aluno coincidirão com seus interesses concretos:

Daí a importância de distinguir, na compreensão dos interesses dos alunos, entre o aluno empírico e o aluno concreto, firmando-se o princípio de que o atendimento aos interesses dos alunos deve corresponder sempre aos interesses do aluno concreto. $\mathrm{O}$ aluno empírico pode querer determinadas coisas, pode ter interesses que não necessariamente correspondem aos seus interesses concretos. É nesse âmbito que se situa o problema do conhecimento sistematizado, que é produzido historicamente e integra o conjunto dos meios de produção. Esse conhecimento sistematizado pode não ser do interesse do aluno empírico, ou seja, o aluno, em termos imediatos, pode não ter interesse no domínio desse conhecimento; mas ele corresponde diretamente aos interesses do aluno concreto, pois enquanto síntese das relações sociais, o aluno está situado numa sociedade que põe a exigência do domínio desse tipo de conhecimento. E é, sem dúvida, tarefa precípua da escola viabilizar o acesso a esse tipo de saber. (SAVIANI, 2015, p. 80)

Cabe ao professor, portanto, a clareza do papel da escola, enquanto instituição formal de educação e de seu papel fundamental no planejamento de ações com intencionalidades específicas no sentido de assegurar aos alunos a assimilação dos conhecimentos. O professor deverá garantir que os conhecimentos sejam adquiridos, "às vezes mesmo contra a vontade imediata da criança, que espontaneamente não tem condições de enveredar para a realização dos esforços necessários à aquisição de conteúdos mais ricos" (SAVIANI, 2008, p. 40).

O professor precisa reconhecer que sem a aquisição desses conhecimentos o indivíduo será privado de sua participação na sociedade e o caráter de humanização presente na transmissão dos conhecimentos, já que por meio desse processo o homem acessa os conhecimentos produzidos pela humanidade ao longo da história a partir das demandas por objetivação.

Ressalta-se que o professor da pedagogia histórico-crítica deve ser um estudioso e manter-se atualizado, conhecendo de forma complexa os conteúdos que vai ensinar, já que não se ensina o que não se sabe. Cabe, ainda, ao professor compreender que os conhecimentos que, na escola, serão transformados em saberes escolares, carregam em si todo o processo histórico de sua elaboração e que passarão a fazer sentido para o aluno à medida que ele acesse e esse compreenda esse processo. $\mathrm{O}$ professor deve planejar suas aulas sempre a partir de intencionalidades claras de ensino considerando as especificidades de cada conhecimento que influenciarão a forma de ensiná-los.

\section{Qual é o conteúdo?}

A pedagogia histórico-crítica ao defender o acesso da classe trabalhadora ao patrimônio cultural humano historicamente desenvolvido, como condição para a transformação social, coloca o 
conteúdo como fundamental no processo de educação formal, uma vez que a aquisição de conteúdos pelos alunos passa a ser central no processo educativo. Explicita-se a assunção dos conteúdos, dos conhecimentos historicamente produzidos pela humanidade em seus processos de objetivação, como centrais na educação escolar:

Parece-me, pois, fundamental que se entenda isso e que, no interior da escola, nós atuemos segundo essa máxima: a prioridade dos conteúdos, que é a única forma de lutar contra a farsa do ensino. Por que esses conteúdos são prioritários? Justamente porque o domínio da cultura constitui instrumento indispensável para a participação política das massas. Se os membros das camadas populares não dominam os conteúdos culturais, eles não podem fazer valer os seus interesses, porque ficam desarmados contra os dominadores, que se servem exatamente desses conteúdos culturais para legitimar e consolidar sua dominação. Eu costumo, às vezes, enunciar isso da seguinte forma: o dominado não se liberta se ele não vier a dominar aquilo que os dominantes dominam. Então, dominar o que os dominantes dominam é condição de libertação. (SAVIANI, 2008, p. 45)

Nessa perspectiva, o acesso aos conhecimentos caracteriza-se como condição de humanização e emancipação. Pode-se recorrer à Lígia Márcia Martins (2013) para entender o acesso aos conhecimentos produzidos pelo homem em suas formas mais desenvolvidas como condição para o processo de humanização:

Aos seres humanos não basta a mera pertença à espécie biológica nem o contato om a sociedade pelas suas bordas. Para que se constituam como tal (seres humanos) precisam apropriar-se da vasta gama de produtos materiais e intelectuais produzida pelo trabalho dos homens ao longo da história. (MARTINS, 2013, p. 24)

Tendo como aporte a Psicologia históricocultural, que se identifica coma Pedagogia históricocrítica, por serem ambas teorias que surgem em contextos de questionamentos e luta pela superação do capitalismo e por assumirem o desenvolvimento histórico-social do gênero humano. Nesse sentido, contribui Duarte (2016, p.37):

Essa teoria psicológica surgiu num contexto revolucionário de luta pela superação do capitalismo e pela construção do socialismo como uma sociedade de transição para o comunismo. $\mathrm{O}$ fato de que não se tenha alcançado o comunismo, que o projeto soviético de socialismo tenha enfrentado uma série de problemas e contradições que levaram à sua derrocada, não muda o que acabei de afirmar, ou seja, que a psicologia histórico-cultural surgiu num contexto social, político e ideológico de luta pela construção do socialismo. Assim, uma pedagogia compatível com essa psicologia deve ser uma pedagogia marxista que situe a educação escolar na perspectiva de superação revolucionária da sociedade capitalista em direção ao socialismo e deste ao comunismo.

A pedagogia histórico-crítica e a psicologia histórico-cultural coadunam ao assumirem a aquisição dos conhecimentos historicamente construídos como fundamentais para o desenvolvimento humano:

Tomamos, como hipótese central, aquilo que, no cerne do preceito vigotskiano segundo o qual o desenvolvimento do psiquismo humano identifica-se com a formação dos comportamentos complexos culturalmente instituídos - com a formação das funções psíquicas superiores - radica a afirmação do ensino sistematicamente orientado à transmissão dos conceitos científicos, não cotidianos, tal como preconizado pela pedagogia históricocrítica. Ou seja, inferimos que para a psicologia histórico-cultural a natureza dos conteúdos e das atividades escolares é variável interveniente na qualidade do desenvolvimento psíquico dos indivíduos, dado que identifica seus postulados às proposições da pedagogia histórico-crítica. (MARTINS, 2015, p. 7)

É válido destacar que a pedagogia históricocrítica e a psicologia histórico-cultural, tendo ambas o materialismo histórico-dialético como fundamento metodológico, assumem a materialidade social do desenvolvimento humano, nos apresentando "o homem como um ser social cujo desenvolvimento condiciona-se pela atividade que o vincula à natureza, um ser que a princípio não dispõe de propriedades que lhe assegurem, por si mesmas, a conquista daquilo que o caracteriza como humano" (MARTINS, 2016). Dessa forma, o desenvolvimento humano será aqui entendido como um processo condicionado às relações históricas, sociais e culturais e não, natural e biológico, ainda que, não negue a dimensão biológica, as bases materiais e orgânicas do desenvolvimento.

Nesse contexto, emergem as considerações de Luria, que aborda a aquisição dos conhecimentos produzidos pelos homens ao longo da história como 
uma das principais características que diferenciam a atividade consciente do homem do comportamento animal:

Diferentemente do animal, cujo comportamento tem apenas duas fontes - 1) os programas hereditários de comportamento, jacentes no genótipo e 2) os resultados da experiência individual -, a atividade consciente do homem possui ainda uma terceira fonte: a grande maioria dos conhecimentos e habilidades do homem se forma por meio da assimilação da experiência de toda a humanidade, acumulada no processo da história social e transmissível no processo de aprendizagem. (LURIA, 1979, p. 73)

Para que seja possível compreender a assimilação dos conteúdos como condição para a emancipação é fundamental que se reporte à ideia de que os conhecimentos, na sociedade capitalista, compõe os meios de produção, portanto, a socialização dos conhecimentos, na escola transformados em conteúdos escolares, ou seja, em saberes escolares, constitui meio de emancipação, uma vez que os dominantes utilizam os conhecimentos como ferramentas de controle e dominação. A seleção dos conteúdos escolares deve, portanto, considerar a garantia aos alunos da assimilação da experiência histórico-social de gerações. Não serão quaisquer conteúdos, mas sim, os conhecimentos historicamente sistematizados em suas formas mais desenvolvidas:

Concebemos como conhecimentos de ensino os conhecimentos mais elaborados e representativos das máximas conquistas dos homens, ou seja, componentes do acervo científico, tecnológico, ético, estético, etc. convertidos em saberes escolares. (MARTINS, 2013, p. 2)

Lígia Márcia Martins (2013) classifica os conteúdos escolares em conteúdos de formação operacional e conteúdos de formação teórica, considerando os primeiros como predominantes na primeira infância e os de formação teórica como predominantes nos demais períodos da escolarização.

Os conteúdos de formação operacional são conteúdos de interferência indireta, que interferem diretamente na constituição de novas habilidades na criança. Dessa forma, são os saberes do professor que garantem a qualificação do ensino, os conhecimentos não são transmitidos às crianças em seu conteúdo conceitual. De acordo com Martins:

Aos conteúdos de interferência indireta denominamos conteúdos de formação operacional, que compreendem os saberes interdisciplinares que devem estar sob o domínio do professor e subjacentes às atividades disponibilizadas aos alunos. Incluem os saberes pedagógicos, sociológicos, psicológicos, de saúde, etc. Esses conhecimentos não serão transmitidos às crianças em seu conteúdo conceitual e nesse sentido é que promoverão, nelas, o que classificamos como aprendizagem indireta. Ao serem disponibilizados, incidem na propulsão do desenvolvimento de novos domínios psicofísicos e sociais expressos em habilidades específicas constitutivas da criança como ser histórico social, a exemplo de: autocuidados, hábitos alimentares saudáveis, destreza psicomotora, acuidade perceptiva e sensorial, habilidades de comunicação. (MARTINS, 2013, p. 3)

Já os conteúdos de formação teórica são conteúdos de interferência direta, "que compreendem os domínios das várias áreas do saber científico transpostos sob a forma de saberes escolares" (MARTINS, 2013, p. 4). São conteúdos que deverão ser ensinados diretamente aos indivíduos de forma direta e sistemática.

Tais conhecimentos corroboram para aquisições culturais mais elaboradas, tendo em vista a superação gradual de conhecimentos sincréticos e espontâneos em direção à apropriação teóricoprática do patrimônio intelectual da humanidade. (MARTINS, 2013, p. 4)

Os conteúdos de formação operacional atuam diretamente no desenvolvimento das funções inatas, nos processos psicológicos elementares e terão influência indireta na elaboração de conceitos. Os conteúdos de formação teórica, por sua vez, ao promoverem a apropriação de conhecimentos interferem indiretamente no desenvolvimento das funções psicológicas.

Outrossim, é válido frisar que na pedagogia histórico-crítica os conteúdos não serão entendidos como na escola tradicional: desatualizados, desconectados da prática social, mecânicos, abstratos, fixos. Serão conteúdos objetivos vivos, reais, dinâmicos, atualizados, conectados à prática social, mas sem que sejam selecionados considerando-se uma utilização imediata, numa perspectiva pragmática e simplista. 


\section{Qual é o currículo?}

A pedagogia histórico-crítica busca romper com a ideia de currículo como tudo o que se faz na escola, adotando uma perspectiva na qual o currículo deve ser composto pelas atividades essenciais que a escola deve desenvolver para manter sua especificidade de instituição formal de educação à qual compete a socialização dos conhecimentos historicamente produzidos pela humanidade em suas formas mais desenvolvidas.

Dessa forma, faz-se necessária uma distinção entre conteúdos curriculares e extracurriculares, distinguindo o que é prioritário e o que é complementar, para que atividades que não garantam a socialização dos conhecimentos não sejam tratadas na escola como fundamentais, em detrimento daquelas que garantem a especificidade da escola.

O currículo deverá, portanto, conter os conteúdos clássicos ${ }^{1}$ da escola: deverá oferecer de forma intencional e sistematizada os conhecimentos artísticos, científicos e filosóficos, assegurando a alfabetização, a matemática e os conteúdos das ciências naturais e sociais, garantindo a apropriação do legado cultural produzido pela humanidade. Saviani assevera:

A escola existe, pois, para propiciar a aquisição dos instrumentos que possibilitam o acesso ao saber elaborado (ciência), bem como o próprio acesso aos rudimentos desse saber. As atividades da escola básica devem organizar-se a partir dessa questão. Se chamarmos isso de currículo, poderemos então afirmar que é a partir do saber sistematizado que se estrutura o currículo da escola elementar. Ora, o saber sistematizado, a cultura erudita, é uma cultura letrada. Daí que a primeira exigência para o acesso a esse tipo de saber seja aprender a ler e escrever. Além disso, é preciso conhecer também a linguagem dos números, a linguagem da natureza e a linguagem da sociedade. Está aí o conteúdo fundamental da escola elementar: ler, escrever, contar, os rudimentos das ciências naturais e das ciências sociais (história e geografia). (SAVIANI, 2013, p. 14)

É no currículo que os conhecimentos serão descritos dosados, organizados de maneira lógica, racional e intencional.

As disciplinas correspondem ao momento analítico em que necessito identificar os diferentes elementos. É o momento em que diferencio a matemática da biologia, da sociologia, da história, da geografia. No entanto, elas nunca se dissociam. Numa visão sincrética, isso tudo parece caótico, parece que tudo está em tudo. Mas na visão sintética percebe-se com clareza como a matemática se relaciona com a sociologia, com a história, com a geografia e vice-versa. (SAVIANI, 2013, p. 124)

Nesse contexto, a definição dos conhecimentos que comporão o currículo corresponderá à definição do ponto de chegada do processo educativo, que terá que se diferenciar do ponto de partida. O ponto de chegada deverá ser o acesso dos indivíduos à cultura erudita, já que, se a cultura popular já é de domínio da população, que função terá a escola se só trabalhar para reproduzi-la em seu interior? A cultura popular é fundamental como ponto de partida do processo pedagógico, no entanto, "para desenvolver cultura popular, essa cultura assistemática e espontânea, o povo não precisa da escola. Ele a desenvolve por obra de suas próprias lutas, relações e práticas" (SAVIANI, 2013, p. 69).

Cabe não desvalorizar o saber popular, mas tomá-lo como ponto de partida, cuidando de não se perder de vista a especificidade da escola. Por conseguinte, é fundamental que se busque a ruptura da dicotomia entre saber popular e saber erudito, como assevera Saviani:

O que hoje é denominado "saber burguês" é um saber do qual a burguesia se apropriou e colocou a serviço de seus interesses. Em suma, o que parece importante entender é o seguinte: essa dicotomia entre saber erudito como saber da dominação e saber popular como saber autêntico próprio da libertação é uma dicotomia falsa. Nem o saber erudito é totalmente burguês, dominante, nem a cultura popular é puramente popular. A cultura popular incorpora elementos da ideologia e da cultura dominantes que, ao se converterem em senso comum, penetram nas massas. (SAVIANI, 2013, p. 69)

Outrossim, é válido salientar que o currículo na perspectiva da pedagogia histórico-crítica será a expressão dos saberes objetivos constituídos historicamente, convertidos em saberes escolares, sistematizados e organizados de modo intencional para a garantia da assimilação pelos alunos, por meio das práticas de ensino realizadas pelo professor. Cabe ainda, ressaltar o valor desses saberes e de sua assimilação pelos alunos enquanto condição para o desenvolvimento das funções 
psicológicas superiores, da humanização:

[...] a correta organização do processo de ensino pelo professor por meio de conhecimentos científicos, ocorridos no espaço escolar, favorece o desenvolvimento psíquico. Ao se criarem condições favoráveis, por meio do currículo escolar, para o desenvolvimento das funções psicológicas superiores dos indivíduos, esses passam a promover a compreensão articulada da realidade objetiva da qual fazem parte. (MALANCHEN, 2016, p. 183)

Por fim, é necessário destacar que o currículo da pedagogia histórico-crítica será um instrumento de luta a serviço da classe trabalhadora, articulado com seus interesses na luta pela transformação social, contra os interesses hegemônicos da classe dominante, pela participação política das massas, como ressalta Saviani:

Justamente porque domínio da cultura constitui instrumento indispensável para a participação política das massas. Se os membros das camadas populares não dominam os conteúdos culturais, eles não podem fazer valer os seus interesses, porque ficam desarmados contra os dominadores, que se servem exatamente desses conteúdos culturais para legitimar e consolidar sua dominação. (SAVIANI, 2008, p. 45)

Em suma, será um currículo vivo, histórica e socialmente situado, elaborado intencionalmente tendo o ato de ensinar que ocorre na instituição formal escola como instrumento de humanização dos indivíduos e destarte, de transformação social, numa perspectiva que nega o imobilismo e a neutralidade.

\section{Qual é o método?}

Para pensar em um método que venha a servir à pedagogia histórico-crítica, Saviani traz no livro Escola e Democracia uma detalhada e fundamental reflexão sobre os métodos tradicionais e novos e a possibilidade de superação de ambos por meio da pedagogia histórico-crítica, que "situarse-ão para além dos métodos tradicionais e novos, superando por incorporação as contribuições de uns e de outros" (SAVIANI, 2008, p.56).

Saviani (2008) delineia uma historicização da educação e da escola moderna descrevendo as características e bases filosóficas dos métodos tradicionais e novos destacando os interesses aos quais ambos os métodos serviam.
De acordo com os apontamentos de Saviani (2008), os métodos tradicionais, com a escola tradicional, surgem para atenderem aos interesses da burguesia que ao ascender ao poder, na intenção de instalação da nova ordem democrática, utiliza a escolarização dos homens como meio para a transformação de servos em cidadãos. Cabe destacar o caráter revolucionário da escola tradicional que surge em um contexto de profunda transformação social. As bases filosóficas remontam à filosofia essencialista que se funda na defesa da igualdade essencial dos homens:

Naquele momento, a burguesia colocava-se na direção do desenvolvimento da história e seus interesses coincidiam com os interesses do novo, com os interesses da transformação; e é nesse sentido que a filosofia da essência, que vai ter depois como consequência a pedagogia da essência, vai fazer uma defesa intransigente da igualdade essencial dos homens. Sobre essa base da igualdade dos homens, de todos os homens, é que se funda então a liberdade, e é sobre, justamente, a liberdade que vai postular a reforma da sociedade. (SAVIANI, 2008, p. 32)

Os métodos tradicionais privilegiam a transmissão dos conhecimentos e centralizam o processo de ensino no professor, detentor dos conhecimentos que serão transmitidos aos alunos. Há prevalência dos conteúdos, dos aspectos lógicos, da disciplina. Saviani destaca o caráter científico dos métodos tradicionais relacionando-os ao método científico indutivo, formulado por Bacon, que contempla três momentos fundamentais: a observação, a generalização e a confirmação. Descreve, ainda, o método da pedagogia tradicional em sua relação com a teoria de Herbart que seria base para a formulação do método expositivo, base do método tradicional: preparação, apresentação, comparação, assimilação, generalização e aplicação.

Com o desenvolvimento da sociedade burguesa e sua ascensão ao poder, essa passa a não mais ter interesse na transformação da sociedade, intencionando a perpetuação da ordem vigente, destarte, a escola tradicional passa a não mais lhe servir. A burguesia passando de classe revolucionária à classe reacionária passa a negar a pedagogia da essência, que até então defendia. Defende, a partir de então, uma pedagogia da existência: não há mais uma igualdade essencial entre os homens, mas sim uma desigualdade que tem que ser respeitada.

Ora, vejam vocês: o que é a pedagogia da 
existência senão diferentemente da pedagogia da essência, que é uma pedagogia que se fundava no igualitarismo, uma pedagogia de legitimação das desigualdades? Com base nesse tipo de pedagogia, considera-se que os homens são essencialmente diferentes, e nós temos que respeitar as diferenças entre os homens. Então, há aqueles que têm mais capacidade e aqueles que têm menos capacidade; há aqueles que aprendem mais devagar; há aqueles que se interessam por isso e os que se interessam por aquilo. (SAVIANI, 2008, p. 34)

Destarte, surgem os movimentos escolanovistas que atuam em defesa de uma educação escolar na qual a centralidade esteja no aluno, nos procedimentos e no aspecto psicológico. O processo de transmissão de conhecimentos da escola tradicional é substituído por processos de fazer de conta, nos quais o aluno é pesquisador, mobilizado por seus próprios interesses e curiosidades. O ensino passa a se confundir com um processo de pesquisa, o que o torna artificial. Nesse sentido, em função da ideia de que o aluno deve construir seu conhecimento, de forma ativa, descobrir por si mesmo, negando-se o ensino, a transmissão dos produtos da ciência e em contrapartida, valorizando-se o processo de desenvolvimento da ciência, como explica Saviani:

Em outros termos, a Escola Nova buscou considerar o ensino como um processo de pesquisa; daí por que ele se assenta no pressuposto de que os assuntos de que se trata o ensino são problemas, isto é, são assuntos desconhecidos não apenas pelo aluno, como também pelo professor. Nesse sentido, o ensino seria o desenvolvimento de uma espécie de projeto de pesquisa, quer dizer, uma atividade vamos aos cinco passos do ensino novo que se contrapõe simetricamente aos passos do ensino tradicional: então, o ensino seria uma atividade $\left(1^{\circ}\right.$ passo $)$ que, suscitando determinado problema ( $2^{\circ}$ passo), provocaria o levantamento dos dados ( $3^{\circ}$ passo), a partir dos quais seriam formuladas as hipóteses ( $4^{\circ}$ passo) explicativas do problema em questão, empreendendo alunos e professores, conjuntamente, a experimentação ( $5^{\circ}$ passo), que permitiria confirmar ou rejeitar as hipóteses formuladas. (SAVIANI, 2008, p. 37)

Saviani, 2008, segue afirmando que essa confusão entre ensino e pesquisa acabou por enfraquecer e empobrecer o ensino e inviabilizar tanto a pesquisa:
Vejam bem, se a pesquisa é incursão no desconhecido, e por isso ela não pode estar atrelada a esquemas rigidamente lógicos e preconcebidos, também é verdade que: no primeiro, o desconhecido só se define no confronto com o conhecido, isto é, se não se domina o já conhecido não é possível detectar o ainda não conhecido, a fim de incorporá-lo, mediante a pesquisa, ao domínio do já conhecido. Aí, parece-me que esta é uma das grandes fraquezas dos métodos novos. Sem o domínio do conhecido não é possível incursionar no desconhecido. E aí está também a grande força do ensino tradicional: a incursão no desconhecido fazia-se sempre por meio do conhecido, e isso é muito simples; qualquer aprendiz de pesquisador passou por isso ou está passando, e qualquer pesquisador sabe muito bem que ninguém chega a ser pesquisador, a ser cientista, se ele não domina os conhecimentos já existentes na área em que ele se propõe a ser investigador, a ser cientista. (SAVIANI, 2008, p. 39)

Por conseguinte, a adesão ao ideário escolanovista resulta na ampliação da qualidade do ensino destinado à classe dominante em oposição à queda na qualidade do ensino das camadas populares, fazendo surgir, portanto, um processo de recomposição da hegemonia da classe burguesa.

Saviani (2008) utiliza a teoria da curvatura da vara, de Lênin, para mostrar como a forma de ver e fazer educação transformou-se, indo de um extremo ao outro, fazendo-se necessário um movimento de equilíbrio: o surgimento de uma pedagogia revolucionária, que lute contra os mecanismos de hegemonia. É nesse sentido que se busca formular a pedagogia histórico-crítica e pensar em um método para esta compreende pensar que:

Serão métodos que estimularão a atividade e iniciativa dos alunos sem abrir mão, porém, da iniciativa do professor, favorecerão o diálogo dos alunos entre si e com o professor, mas sem deixar de valorizar o diálogo com a cultura acumulada historicamente; levarão em conta o interesse dos alunos, os ritmos de aprendizagem e o desenvolvimento psicológico, mas sem perder de vista a sistematização lógica dos conhecimentos, sua ordenação e gradação para efeitos do processo de transmissão-assimilação dos conteúdos cognitivos. (SAVIANI, 2008, p. 56) 
Ressalta-se, no entanto, que o método da Pedagogia histórico-crítica, de forma alguma, seria um misto das pedagogias tradicional e nova, embora deva incorporar aspectos das duas. A pedagogia histórico-crítica "mantém continuamente presente a vinculação entre educação e sociedade" (SAVIANI, 2008 , p. 56) em oposição às pedagogias nova e tradicional que implicam uma autonomização das pedagogias em relação à sociedade.

Ainda no livro Escola e democracia, Saviani (2008) propõe cinco passos que comporão o método da pedagogia histórico-crítica: prática social inicial, problematização, instrumentalização, catarse e prática social. Tais passos partem de um conceito de educação como atividade mediadora no seio da prática social global, tendo, portanto, a prática social como ponto e partida e ponto de chegada do processo educativo. Acerca do método, assevera Saviani:

$\mathrm{O}$ método aqui preconizado tem professores e alunos como agentes sociais: o ponto de partida do ensino, passa a ser, não a preparação dos alunos cuja iniciativa é do professor, como no método tradicional, nem a atividade que é de iniciativa do aluno, como no método novo, mas sim prática social (primeiro passo) que é comum a professor e alunos. (SAVIANI, 2008, p 56)

A prática social inicial, primeiro passo do método, é comum a professores e alunos: nesse momento, alunos têm uma visão sincrética do todo do conhecimento que será aprendido, enquanto o professor tem uma compreensão sintética precária, como explica Saviani:

O professor, de um lado, e os alunos, de outro, encontram-se em níveis diferentes de compreensão (conhecimento e experiência) da prática social. Enquanto o professor tem uma compreensão que poderíamos denominar de "síntese precária", a compreensão dos alunos é de caráter sincrético. A compreensão do professor é sintética porque implica uma certa articulação dos conhecimentos e das experiências que detém relativamente à prática social. Tal síntese, porém, é precária, uma vez que, por mais articulados que sejam os conhecimentos e as experiências, a inserção de sua própria prática pedagógica como uma dimensão da prática social envolve uma antecipação do que lhe será possível fazer com os alunos cujos níveis de compreensão ele não pode conhecer, no ponto de partida, senão for de forma precária. Por seu lado, a compreensão dos alunos é sincrética uma vez que, por mais conhecimentos e experiências que detenham, sua própria condição de alunos implica uma impossibilidade, no ponto de partida, de articulação da experiência pedagógica na prática social que participam. (SAVIANI, 2008, p. 56)

Já como o segundo passo do método, temos a problematização que compreenderá: "a identificação dos principais problemas postos pela prática social. Trata-se de detectar questões que precisam ser resolvidas no âmbito da prática social e, em consequência, que conhecimento é necessário dominar" (SAVIANI, 2008, p. 57).

Nesse momento do processo a prática social será analisada confrontando-se o conteúdo que será trabalhado e suas condições de aplicação social, realizando-se a seleção de quais abordagens do conteúdo são fundamentais. Será, portanto, “o momento de questionar o conteúdo e especificar as razões pelas quais deve ser apropriado pelos alunos, explicitando ao mesmo tempo suas múltiplas dimensões" (GASPARIN, 2015, p. 39).

O terceiro passo é a instrumentalização, momento no qual ocorrerá a apropriação dos instrumentos teóricos e práticos necessários ao equacionamento dos problemas da prática social, já detectados e problematizados. "Trata-se da apropriação pelas camadas populares das ferramentas culturais necessárias à luta social que travam diuturnamente para se libertar das condições de exploração em que vivem" (SAVIANI, 2008, p. 57). Sobre a instrumentalização, Gasparin destaca:

A instrumentalização é o caminho pelo qual o conteúdo sistematizado é posto à disposição dos alunos para que o assimilem e o recriem e, ao incorporá-lo, transformem-no em instrumento de construção pessoal e profissional. Nessa atividade, os alunos estabelecem uma comparação intelectual entre seus conhecimentos cotidianos e os conhecimentos científicos, apresentados pelo professor, possibilitando que eles incorporem esses conhecimentos. Nesse processo o professor auxilia os alunos a elaborarem a representação mental do objeto do conhecimento. Esse é o momento do saber fazer docente-discente, em sala de aula, evidenciando que o estudo dos conteúdos propostos está em função das respostas a serem dadas às questões da prática social. (GASPARIN, 2015, p. 51)

O quarto passo do método proposto por Saviani (2008) é a catarse, que caracterizará a culminância do processo educativo. A catarse é 
descrita por Saviani:

Adquiridos os instrumentos básicos, ainda que parcialmente, é chegado o momento da expressão elaborada da nova forma de entendimento da prática social a que se ascendeu. Chamemos esse quarto passo de catarse, entendida na acepção gramsciana de "elaboração superior da estrutura em superestrutura na consciência dos homens" (GRAMSCI, 1978, p. 53). Trata-se da efetiva incorporação dos instrumentos culturais, transformados agora em elementos ativos de transformação social. (SAVIANI, 2008, p. 57)

Dessa forma, a catarse configurará na expressão da aprendizagem do conteúdo pelo aluno. Embora ela ocorra durante todo o processo de ensino, é no momento catártico que a assimilação do conhecimento pelo aluno fica evidenciada.

É válido ressaltar que os passos propostos não devem ser compreendidos como algo que será seguido de forma linear ou cronológica, mas "é mais apropriado falar aí de momentos articulados num mesmo movimento, único e orgânico" (SAVIANI, 2008. p. 60). Não se deve, portanto, incidir no equívoco de que o momento catártico só acontecerá ao final do processo de ensino, devendo ficar claro que durante todo o processo de ensino pode e deve ocorrer assimilação e expressão do conhecimento pelos alunos.

Nos passos descritos por Saviani, fica explícito o materialismo histórico-dialético como base filosófica da pedagogia histórico-crítica, tendo a concepção dialética marxista de ciência como referencial para o método: o método de ensino considerará que o movimento de assimilação dos conhecimentos "vai da síncrese ("visão caótica do todo") à síntese ( uma rica totalidade de determinações e de relações numerosas") pela mediação da análise ("as abstrações e determinações mais simples")" (SAVIANI, 2008, p. 59, grifos do autor).

\section{Conclusão}

Em suma, cabe ressaltar a importância de compreender a pedagogia histórico-crítica como uma pedagogia a serviço dos interesses da classe trabalhadora, a serviço da luta pela transformação social e que se posiciona na busca por uma sociedade socialista.É uma pedagogia que deseja e projeta uma escola que garanta o desenvolvimento máximo das potencialidades dos estudantes da classe trabalhadora. É uma pedagogia comunista à medida que busca articular-se com a luta da classe trabalhadora pela superação da sociedade capitalista.

É uma pedagogia contra hegemônica, que assume a luta de classes na educação e a reconhece na escola. Está consubstanciada nas teorias marxistas e assume o materialismo históricodialético como base filosófica.

Por conseguinte, valoriza a escola e sua especificidade: a escola é tomada como instituição formal de ensino, que serve à socialização dos conhecimentos produzidos pelo homem em suas formas mais desenvolvidas. $O$ acesso a esses conhecimentos, de modo intencional, por meio de uma organização sistemática é função da escola e condição para o desenvolvimento psíquico dos indivíduos, ou seja, do desenvolvimento das funções psíquicas superiores, como explicita a Psicologia histórico-cultural que serve de aporte teórico à Pedagogia histórico-crítica.

A escola que assume a pedagogia históricocrítica é uma escola que se contrapõe às perspectivas de ensino espontaneístas e que, destarte, reconhece a importância da transmissão dos conhecimentos para a formação do gênero humano, considerando que essa transmissão não é um processo passivo para o aluno.

\section{Referências}

DUARTE, Newton. Vigotski e o "aprender a aprender". Crítica às apropriações neoliberais e pós-modernas da teoria vigotskiana. 5.ed. Campinas: Autores associados, 2011.

. Os conteúdos escolares e a

ressureição dos mortos- contribuição à teoria histórico-crítica do currículo. 1.ed. Campinas: Autores associados, 2016.

GASPARIN, João Luiz. Uma didática para a pedagogia histórico-crítica. 5. ed. Campinas: Autores Associados, 2015.

LIMA, M.R.; BATISTA, E.L. A pedagogia histórico-crítica como teoria pedagógica transformadora. In: MARSIGLIA, Ana Carolina Galvão; BATISTA, Eraldo Leme [orgs.]. Pedagogia histórico-crítica desafios e perspectivas para uma educação transformadora. 1.ed. Campinas: Autores 
associados, 2012, p. 1-36.

LURIA, Alexander Romanovich. Atividade consciente do homem e suas Raízes HistóricoSociais. Curso de Psicologia Geral, vol.1, 1979, p. $71-84$.

MALANCHEN. Júlia. Cultura, conhecimento $e$ currículo - contribuições da pedagogia Históricocrítica. 1. ed. Campinas. 2016.

MARTINS, Lígia Márcia. Contribuições da psicologia histórico-cultural para a pedagogia histórico-crítica. Revista HISTEDBROn-line, Campinas, $\mathrm{n}^{\circ}$ 52, p. 286-300, 2013.

O desenvolvimento do psiquismo e a educação escolar - contribuições à luz da psicologia histórico-cultural e da pedagogia histórico-crítica. Campinas: Autores Associados, 2015. . Psicologia histórico-cultural, pedagogia histórico-crítica e desenvolvimento humano. In:
MARTINS, L.M; A.A. ABRANTES; M.G.D. FACCI (Orgs). Periodização histórico-cultural do desenvolvimento psíquico: do nascimento à velhice. Campinas: Autores Associados, 2016.

SAVIANI, Demerval. Escola e Democracia. Edição Comemorativa. Edição Comemorativa. Campinas: Autores Associados, 2008. Pedagogia Histórico-Crítica primeiras aproximações. 11.ed. Campinas: Autores Associados, 2013.

SAVIANI, Dermeval. Marxismo, Educação e Pedagogia. In: SAVIANI, D.; DUARTE, N. (orgs.) Pedagogia histórico-crítica e luta de classes na educação escolar. Campinas: Autores Associados, 2012, p. 59-85.

SAVIANI, Dermeval; DUARTE, Newton. Prefácio. In: SAVIANI, D.; DUARTE, N. (orgs.) Pedagogia histórico-crítica e luta de classes na educação escolar. Campinas: Autores Associados, 2012, p. 111.

\section{Sobre a autora}

Raquel Elisabete de Oliveira Santos: é graduada em Pedagogia pela Faculdade de Educação Padre Anchieta, com especialização em Educação especial e Gestão escolar. É mestranda pela Unesp/SP, Instituto de Arte, na linha de pesquisa: Processos artísticos, experiências educacionais e mediação cultural e realiza pesquisa sobre a implementação da pedagogia histórico-crítica em escola municipal de ensino fundamental da rede municipal de Jundiaí, na qual é diretora há 12 anos. Na rede municipal de ensino de Jundiaí atuou, ainda, como professora de educação básica I e como Coordenadora Pedagógica.

Submetido em julho de 2017.

Aprovado em dezembro de 2017. 